\title{
Applicability of Yellow Pigmented Microbe obtained from Indian Rock Python Fecal Sample as Bio-Ink
}

\author{
J.R. Parvathi*, Shilpa Madhavan and R. Madhan Kumar \\ ${ }^{1}$ School of Biotechnology and Bioinformatics, D. Y. Patil University, Level 5, Sector 15, Plot \\ No. 50, CBD Belapur, Navi Mumbai, Maharashtra 400614, India \\ ${ }^{2}$ Amity Institute of Biotechnology, Amity University, Mumbai, Maharashtra, India \\ ${ }^{3}$ Bharathidasan University Constituent College, Perambalur, Tamil Nadu, India \\ *Corresponding author
}

Keywords

Bio-color,

Micrococcus luteus, Bacterial pigments, Bio-ink.

Article Info

Accepted:

15 March 2017

Available Online:

10 April 2017

\section{A B S T R A C T}

A non-diffusable yellow pigmented isolate (Y_01) was isolated from a week-long enrichment of fecal sample of Indian rock python in cholesterol minimal medium. Basic biochemical characterization followed by $16 \mathrm{~S}$ ribosomal DNA sequencing and Matrix Assisted Laser Desorption/Ionization method led to identification of the isolate as Micrococcus luteus. Nutrient broth ( $\mathrm{pH} 7.4$ ) supplemented with $2.5 \% \mathrm{NaCl}$ was used as the growth medium with incubating conditions of $37^{\circ} \mathrm{C}$ for 24 hours as ideal scenario. The microbial pigment was found to be insoluble in most of the polar and non-polar solvents and resistant to both acid and alkali. The yellow pigment showed durable staining on both glossy and non-glossy papers with absence of spreading in the presence of alcohol and acetone, thus establishing applicability of the same as "bio-ink".

\section{Introduction}

The term evolution stands for the gradual development of life with a cumulative influence of inherent characters, environmental influence and natural selection, each having a significant role to impart. Based on the current scenario, this term seems to be more influenced by environment vagaries brought about by modernization which not only governs change but ultimately life as such. From a wealth of natural assets, increasing demand of development have cost us their decline, paving way to boost research towards utilizing, managing and developing sustainable alternatives. An ocean of change in the nature of components required for one's daily use that vary from renewable energy to recyclable bio-plastic instead of petrochemical products is at a rise. One such mandate for routine life is ink, a quintessential entity for documentation and labeling. The available products of these in market are synthetic; noxious due to heavy metal toxicity, presence of non-renewable oils and volatile organic solvents in it results in 
hazardous side-effects from headaches to nervous damage when ingested (Abishek Kumar et al., 2015). Recent studies have focused on employing microbial pigments as the source of bio-colourants instead of the commonly preferred counterpart, plant pigments (Wan Azlina Ahmad et al., 2012). In comparison to latter, microbial pigments offer rapid and unlimited productivity using standardized medium throughout the year with no seasonal preference (Gunasekaran and Poorniammal, 2008).

Pigmented bacteria exhibits both water soluble (diffuse into the medium) and insoluble pigments (Sarvamangala and Aparna, 2016); that may or may not be fluorescent. Multitudinous primary and secondary color shades (Tibor, 2007) with occasional light or dark tinges of even unusual colors like brown, golden and silver (Sahoo and Panigrahi, 2016) are exhibited by such microbes. The site of synthesis is localised either at cell wall or periplasmic space with chemical composition of bacterial pigments ranging from pyrrole, phenazine, carotenoid, xanthophylls, flavins, monascins, quinine or quinone derivatives, violacein to indigo (Rokade and Pethe, 2016). Pigment production is dependent on environmental and media conditions (Joshi et al., 2003) thus studies carried towards this direction can promote start-ups that involve in biocolour production and management.

The rudimentary idea of developing a water insoluble colourant, anticipated as an opposite for bio-ink, kick started the current work. The possibility of finding the same in fat utilizing niche prompted to target fecal sample of python, the model organism for cholesterol metabolic study (Riquelme, 2011). Series of studies involved in screening pigmented microbes from various environmental sources have been reported, but no attempt for the same with regards to python fecal sample has been ventured. The incipient part of the study deals with enrichment, screening and identification of the pigmented microbe trailed by standardisation of growth conditions to facilitate maximum pigment yield using nutrient broth, a commonly preferred growth medium. The conclusive part of the study succincts the rationale of this probe by exploring the characteristic of microbial pigment obtained from mentioned source for its applicability apropos as bio-ink.

\section{Materials and Methods}

\section{Initial screening with enrichment medium}

For this study, fecal sample of a well feed twenty year old adult male Indian rock python (Python molurus) weighing around $25 \mathrm{~kg}$ was procured from Rajiv Gandhi Zoological Park and Wildlife Research Centre, from Pune. $1 \mathrm{~g}$ of the sample was aseptically transferred into a $10 \mathrm{ml}$ of 0.9 normal saline solution, incubated at $37^{\circ} \mathrm{C}$ for six hrs. As a prestep to enrichment, $5 \mathrm{ml}$ of pre-inoculated saline suspension was aseptically transferred first into $50 \mathrm{ml}$ of Nutrient Broth (NB) and kept for overnight incubation at $37^{\circ} \mathrm{C}$ (work culture). Cholesterol based enrichment medium containing $0.5 \%$ cholesterol (prepared by dissolving $0.5 \mathrm{~g}$ of cholesterol in distilled water using Triton X-100 by heating method) was prepared to mimic a fat niche. $5 \mathrm{ml}$ of the above work culture was aseptically transferred into the four separate flask (E1E4) each containing $50 \mathrm{ml}$ enrichment media; these flasks were kept for incubation at $16^{\circ} \mathrm{C}$, $30^{\circ} \mathrm{C}, 37^{\circ} \mathrm{C}$ and $45^{\circ} \mathrm{C}$ respectively for a week long incubation.

\section{Selection and characterization of candidate microbe}

Serial dilution to a count of five-fold dilutions was prepared from each culture (E1 to E4) using saline and incubated at room 
temperature for $6 \mathrm{hrs}$. $0.1 \mathrm{ml}$ of the each culture was streaked aseptically onto Nutrient Agar (NA) plates using spread plate technique. Among the different dilutions, only one pigmented isolate was observed. The particular colony was "picked up" using nichrome loop and dispensed into $10 \mathrm{ml}$ of nutrient broth and kept for overnight incubation at $37^{\circ} \mathrm{C}$ to obtain pure culture. After assurance of pure culture the same was employed for identification and standardization studies. A string of biochemical tests involving colony morphology, staining techniques, Methyl Red-Voges Proskauer (MR-VP), Indole test, Citrate test, Catalse test, Urea hydrolysis test, Starch hydrolysis test, Gelatin hydrolysis test and Carbohydrate fermentative test was performed. Subsequently molecular assay involving DNA and proteomic based method was executed to confirm the identity of selected isolate. 16S $r$ RNA sequencing with $27 \mathrm{~F}$ and $1492 \mathrm{R}$ primers followed by reference of amplicons using BLAST was employed for DNA based assay. Proteomic based identification method employed Matrix assisted laser desorption-ionization-time-offlight mass spectrometry (MALDI-TOF MS) where the bacterial isolates from agar plate were directly extracted using Ethanol/ Formic acid as per the description of Bruker Daltonic MALDI-TOF biotyper analysis, Germany. The results obtained as spectra were matched with the database of Bruker (version 2.0).

\section{Standardisation of growth conditions}

For reassurance of the optimal temperature for Y_01 growth, $100 \mu \mathrm{l}$ of the pure culture was streaked on NA plate and kept at $0^{\circ} \mathrm{C}$, $16^{\circ} \mathrm{C}, 28^{\circ} \mathrm{C}, 37^{\circ} \mathrm{C}$ and $45^{\circ} \mathrm{C}$ respectively. After standardization of temperature conditions, the effect of $\mathrm{pH}$ in pigment production was studied by separately inoculating the isolates in NA plates of $\mathrm{pH} 4.5, \mathrm{pH} 5.8, \mathrm{pH} 7.4$ and $\mathrm{pH} 11.5$ followed by overnight incubation at
$37^{0} \mathrm{C}$. NA plates supplemented with $2.5 \%$, $5 \%, 7 \%, 8 \%$ and $10 \% \mathrm{NaCl}$ was set up to study the effect of salt concentration on pigment production. In all cases the growth was recorded for $12 \mathrm{hrs}, 24 \mathrm{hrs}$ and $48 \mathrm{hrs}$.

\section{Solubility and colour reaction tests of pigment for its applicability as bio-ink}

$2 \mathrm{ml}$ of the culture grown under the standardized growth conditions of $\mathrm{pH}$, salt concentration and temperature conditions were aliquoted respectively into eight eppendorf tubes of $1.5 \mathrm{ml}$ capacity each; centrifuged at $2000 \mathrm{rpm}$ for $10 \mathrm{~min}$, supernantant was dispensed and blot dryed. To each of the pellet, different solvents were added and mixed to check the solubility of the pigment. In eppendorf 1 , the pellet was mixed with water, accordingly methanol, ethanol, acetonitrile, acetone, chloroform, toluene, petroleum ether and hexane were added specifically to tube $2,3,4,5,6,7$ and 8 respectively. To confirm the solubility, two trials were formatted, in one set, eppendorffs were kept for 15 min without any heat treatment (trial 1) and for the other, eppendorffs were kept in heating block at $60^{\circ} \mathrm{C}$ for $30 \mathrm{~min}$ (trial 2).

After this time frame, the tubes were centrifuged at $2000 \mathrm{rpm}$ for $10 \mathrm{~min}$ and the supernatant was aliquotted to fresh tubes. For assessing pigment strength, sedimented pigments were scrapped out and laid over four glass slides. Two-three drops of concentrated $12 \mathrm{~N}$ hydrochloric acid ( $\mathrm{HCl})$; was overlaid over the pigment on the first slide and mixed well to see the colour reactions and changes if any. This practice was repeated for other slides with $20 \%$ potassium hydroxide $(\mathrm{KOH})$, $5 \mathrm{~N}$ sodium hydroxide $(\mathrm{NaOH})$ and $1 \%$ potassium permanganate $\left(\mathrm{KMnO}_{4}\right)$ respectively; reactions were duly noted. For preparation of bio-ink, $1 \mathrm{~g}$ of air-dried, heatkilled pellet of the bacterial isolate was mixed with $2 \mathrm{ml}$ of vinegar and $0.5 \mathrm{~g}$ of table salt. 
To appraise usability of the microbial pigment as bio-ink, a comparative analysis with synthetic water colors (Kokuyo Camlin) and pastels (Kokuyo Camlin) was carried out. Each colorants were applied onto both A4 size paper and labels; three drops of water, acetone and alcohol was overlaid using pasteur pipette on to the applied colorants to evaluate the extent of spread and durability of the bio-ink.

\section{Results and Discussion}

After one week long enrichment in cholesterol minimal medium followed by spread plate assay, only a single NA plate containing the consortium from fifth dilution of culture incubated at $37^{\circ} \mathrm{C}$ showed a single well isolated non-diffusible yellow pigmented colony. The isolate was coded as Y_01; Y for yellow and 01 stands for the serial number of the colonies that were observed in that plate. Preliminary characterisation by colony morphology and staining followed by biochemical assays targeting the proteins or the enzymatic products of the isolate helped in providing a signature profile of the particular isolate (Table 1). Defining the identity was trailed by optimizing growth settings with respect to temperature, incubation time and condition, $\mathrm{pH}$ and salt to increase growth of the isolate thus paving way to convalesce more pigment (Table 2).

\section{Identity of Y_01}

The authenticity of the isolate was confirmed by using the de facto barcode $16 \mathrm{~S}$ ribosomal RNA segments (rRNA) (Links et al., 2012) for DNA based studies. The lead-in reason for considering rRNA for studies owes to fact that they are repetitive multicluster regions comprising both diverse and conserved segments within the stretch; former being preferred for diversity studies and the latter for identification studies (Janda and Abbott,
2007). In this context, routine approach of microbial detection involves amplification of bacterial genome with a universal primer followed by sequencing of amplicon and analysis of the sequence draft using Basic Local Alignment Search Tool (BLAST) against the nucleotide reference sequence for rRNA to identify the microbe (Clarridge, 2004). BLAST is an optimized comparative algorithm tool that aligns a query sequence (input data) against data records (subject sequences) by assigning optimal local alignments with high-scoring region to that of input data. The best "hit" or sequence that is uses to identify the query sequence is deduced using expectation/ expect (e-value) and the score of an alignment (S) (Richter et al., 2007). 16S rRNA sequencing gave a read of $1462 \mathrm{bp}$ and BLAST search revealed the isolate as Micrococcus luteus (Acession no: KT339390; 8th August 2015). MALDI-TOF MS is now considered as one of the major criteria for easy and rapid identification of bacterial strains (Bizzini and Greub, 2010), the basis of the detection strategy involves computing the mass $(\mathrm{m})$ to charge $(\mathrm{z}), \mathrm{m} / \mathrm{z}$ values of the ionized proteins released during the partial bacterial cell lysis (Panda et al., 2014).

In the case of whole-cell MS analysis, ribosomal proteins serve as the main target of the analysis together with some other high copy proteins (Krishnamurthy and Ross, 1996). The mass spectra of isolate was 7179.130 from the base line and matched with Micrococcus luteus according to the database of Bruker Daltonik MALDI Biotyper thus confirming the bacterial identity of Y_01. The isolate gave positive test only with catalase even though variants of the candidate microbe evince urease and gelatinase positive at times (Fox, 1976). Thus a cumulative assay employing biochemical and molecular parameters is portentous for bacterial identification. 


\section{Optimal growth conditions of Y_o1}

The bacterium displayed growth at both $30^{\circ} \mathrm{C}$ and $37^{\circ} \mathrm{C}$ but attainted its maximum growth $37^{\circ} \mathrm{C}$ after $12 \mathrm{hrs}$ rather than $24 \mathrm{hrs}$ in both cases. Increased number of pigmented colonies was seen across $\mathrm{pH}$ of 4.5 to 7.4 after 12 hours of incubation but utmost growth was observed at $\mathrm{pH} 7.4$ after $24 \mathrm{hrs}$ of incubation at $37^{\circ} \mathrm{C}$ indicative of favorable condition growth and pigment production is around neutral $\mathrm{pH}$. Prominent growth of the isolate was observed within $12 \mathrm{hrs}$ in $2.5 \% \mathrm{NaCl}$ and in 5\% after $24 \mathrm{hrs}$; but declined growth of the same was seen on increased salt concentrations.

Table.1 Colony and Biochemical characterisation of Y_01

Colony Morphology

\begin{tabular}{|c|c|c|c|}
\hline Aspects & Observation & Test & Observation \\
\hline Configuration & Tetrad & MacConkey agar & White colonies \\
\hline Margin & Entire & Indole test & No change \\
\hline Elevation & Convex & Methyl red test & No colour change \\
\hline Surface & Smooth & Voges Proskauer test & No colour change. \\
\hline Gram reaction & Gram positive & Citrate test & No colour change \\
\hline Position & Pinhead & Starch hydrolysis & No halo zone is formed. \\
\hline Shape & Cocci & Gelatin hydrolysis & Solidify \\
\hline Density & Opaque & Urea hydrolysis & Orange colour \\
\hline \multirow[t]{3}{*}{ Pigmented } & $\begin{array}{l}\text { Yellow and non- } \\
\text { diffusible. }\end{array}$ & Catalase & Effervescence \\
\hline & & Carbohydrate & Colour change to yellow \\
\hline & & Fermentation test & $\begin{array}{l}\text { was observed for the } \\
\text { mentioned sugars except } \\
\text { for lactose }\end{array}$ \\
\hline
\end{tabular}

Biochemical tests 
Table.3a Solubility test of the pigment in

Table.3b Colour reactions with acid and bases different solvents

\begin{tabular}{lllllllll}
\hline \hline S & Solvent & \multicolumn{2}{l}{ Observation } & S & Acid/base & \multicolumn{2}{c}{ Observation } \\
\hline \hline & & Trial 1 & Trial 2 & & & PV & PS & PVS \\
$\mathbf{1}$ & Acetone & $\mathrm{N}$ & $\mathrm{N}$ & 1 & $\begin{array}{l}\text { Distilled } \\
\text { water }\end{array}$ & - & - & - \\
$\mathbf{2}$ & Acetonitrile & $\mathrm{N}$ & $\mathrm{N}$ & 2 & $\mathrm{HCl}$ & - & - & - \\
$\mathbf{3}$ & Chloroform & $\mathrm{N}$ & $\mathrm{N}$ & 3 & $\mathrm{NaOH}$ & - & - & - \\
$\mathbf{4}$ & Distilled water & $\mathrm{N}$ & $\mathrm{N}$ & 4 & $20 \% \mathrm{KOH}$ & - & - & - \\
$\mathbf{5}$ & Ethanol & $\mathrm{N}$ & $\mathrm{N}$ & 5 & KMNO4 & - & - & - \\
$\mathbf{6}$ & Hexane & $\mathrm{N}$ & $\mathrm{N}$ & & & & \\
$\mathbf{7}$ & Methanol & $\mathrm{N}$ & $\mathrm{N}$ & & & & \\
$\mathbf{8}$ & Petroleum ether & $\mathrm{N}$ & $\mathrm{N}$ & & & & \\
$\mathbf{9}$ & Toluene & $\mathrm{N}$ & $\mathrm{N}$ & & & & \\
\hline \hline
\end{tabular}

Trial 1 involves solubility testing without heating and Trial 2 comprises of solubility with heating;

Key: $\mathrm{N}=$ Negative result for the mentioned test, $\mathrm{PV}=$ pigment with Key: N= No solubility seen.

Fig.1 Applicability of microbial pigment as bio-ink across labels (left hand side) and on paper

(right hand side)

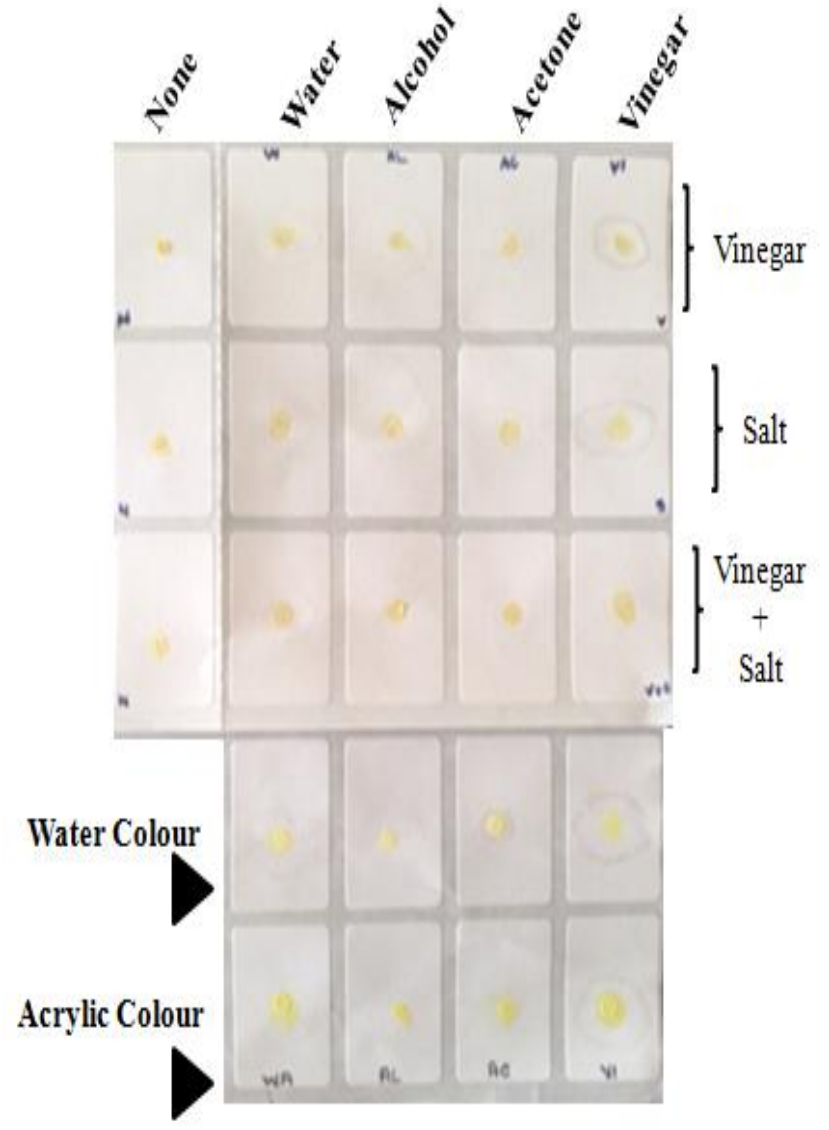

Glossy surface (labels)

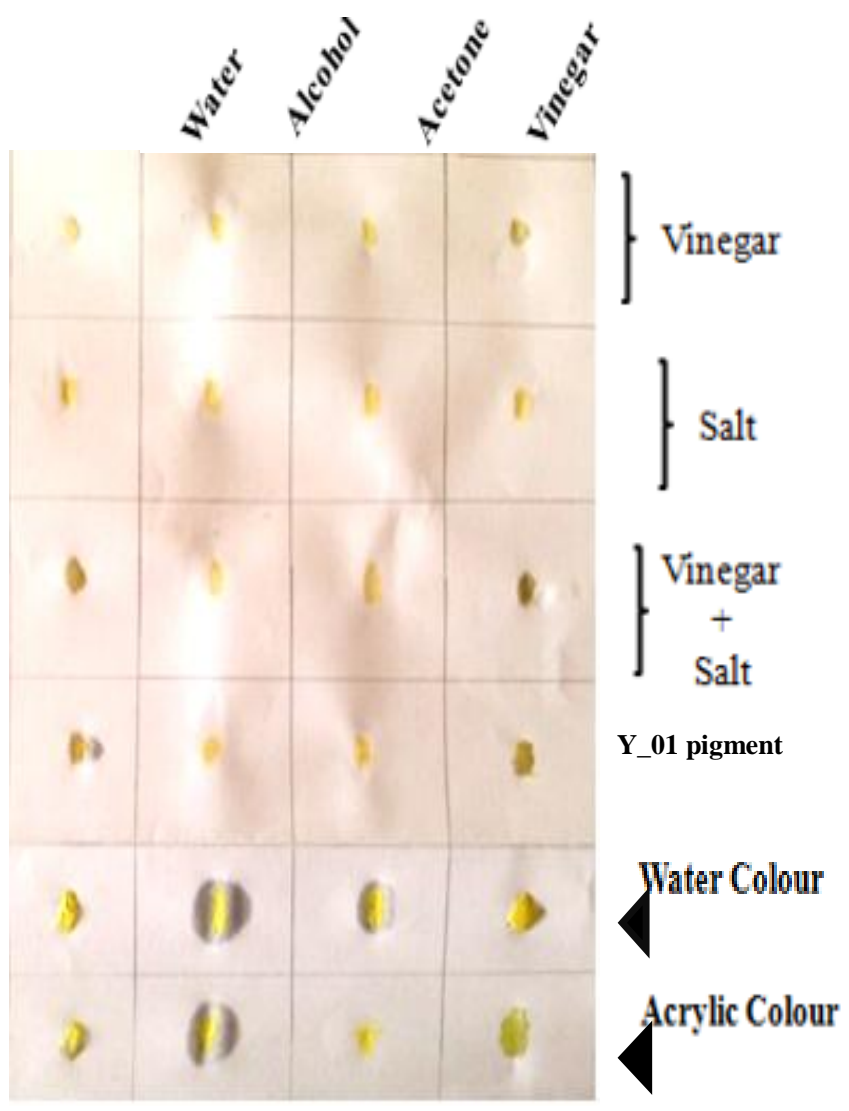

A4 plain paper 


\section{Pigment characterization and applicability}

An attempt to extract the yellow pigment using a range of polar to non-polar (Table 3a) based on the various extraction schemes employing single solvent or solvent mixtures were tried. Dual trials with and without heat treatment bared that the pigment was tolerant to all the non-polar and polar solvents tried. As there are less number of universal and standardized techniques for the extraction of yellow pigments from the bacterial cell, the initiative for the pigment extraction using mixture of solvents was held back for further studies. Since the extraction of pigments was not possible the only alternative left was to use the complete cell in the inactive stage with the intact pigment. As it was observed that the pigment was getting charred upon heating, the solitary approach was the exposure to UV light for 15 mins followed by autoclaving, both being sort-after methods of sterilization (Pattnaik et al., 1997). Treatment of the pigment against acid and bases (Table $3 b)$ confirmed the tolerance nature of the same and indicated the non-suitability of this pigment as a $\mathrm{pH}$ indicator (Bondre et al., 2012).

Primodial practices of applying natural pigments involved addition of common salt and vinegar to increase the binding capacity of colors as well as in checking the growth of microbes by thus extending the shelf life of bio-pigments (Inetianbor et al., 2015; Young et al., 2008). As the focus of the study envisioned in developing a sustainable bio-ink from the yellow pigment obtained Y_01, the applicability of the same was checked for its adherence and binding over the material. In accordance to this, a set of mixtures were produced: pigment with vinegar (PV), pigment with salt (PS) and pigment with vinegar and salt (PVS). All these were applied onto both normal sheet of paper (A4) as well as glossy sticker. A comparative analysis of the same was checked against regular yellow water color and acrylic color by testing the durability of the pigment against solvents like water, vinegar, acetone and alcohol. None of the colorants showed any leaking or spread over the sheets (Fig. 1), rich color of the biopigment matched with that of the water color and acrylic color before and after the treatment with these solvents proving the microbial pigment as an ideal choice as colourant/ink.

Recent studies on environmental microbiology has reverberated sustainability as the need of the hour; plethora of possible utilization of microbes from biosensors to bioplastics or as a source for biocolour as explored in this strive can be the future research for upcoming microbiologist.

\section{References}

Ahmad, W.Z., Yusof, N.Z., Nordin, N., Zakaria, Z.A., Rezali, M.F. 2012. Production and characterization of violacein by locally isolated Chromobacterium violaceum grown in agricultural wastes. Appl. Biochem. Biotechnol., 167(5): 12201234.

Bizzini, A., Greub, G. 2010. Matrix-assisted laser desorption ionization time-of-flight mass spectrometry, a revolution in clinical microbial identification. Clin. Microbiol. Infect., 16(11): 1614-1619.

Bondre, S., Patil, P., Kulkarni, A. 2012. Study on Isolation and purfication of anthocyanin and its application as $\mathrm{pH}$ indicator. IJABR, 3(3): 698-702.

Clarridge, J.E. 2004. Impact of 16 S rRNA Gene Sequence Analysis for Identification of Bacteria on Clinical Microbiology and Infectious Diseases. Clin. Microbiol. Rev., 17(4): 840-862.

Fox, R.H. 1976. Differentiation of Micrococcus luteus and Micrococcus varians on the Basis of Catalase Isoenzymes. J. Gen. Micro., 93(2): 272-277.

Gunasekaran, S., Poorniammal, R. 2008. 
Optimization of fermentation conditions for red pigment production from Penicillium sp. under submerged cultivation. Afr. J. Biotechnol., 7(12): 1894-1898.

Inetianbor, J.E., Yakubu, J.M., Ezeonu, S.C. 2015. Effects of food additives and preservatives on Man- a review. Asian J. Sci. Technol., 6(2): 1118-1135.

Janda, J.M., Abbott, S.L. 2007. 16S rRNA Gene Sequencing for Bacterial Identification in the Diagnostic Laboratory: Pluses, Perils, and Pitfalls. J. Clin. Microbiol., 45(9): 2761-2764.

Joshi, V.K., Attri, D., Bala, A., Bhushan, S. 2003. Microbial pigments. Indian $J$. Biotech., 2: 362-369.

Krishnamurthy, T., Ross, P.L. 1996. Rapid identification of bacteria by direct MALDI mass spectrometric analysis of whole cells. Rapid. Commun. Mass. Spectrom., 10(15): 1992-1996.

Kumar, A., Vishwakarma, H., Singh, J., Dwivedi, S., Kumar, M. 2015. Microbial pigments: production and their applications in various industries. IJPCBS, 5(1): 203-212.

Links, M.G., Dumonceaux, T. J., Hemmingsen, S.M., Hill, J.E. 2012. The Chaperonin-60 Universal Target is as a Barcode for Bacteria That Enables De Novo Assembly of Meta genomic Sequence Data. PLoS ONE, 7(11): e49755. doi:10.1371/journal.pone.0049755

Panda, A., Kurapati, S., Samantaray, J.C., Srinivasan, A., Khalil, S. 2014. MALDITOF Mass spectrometry proteomic based identification of clinical bacterial isolates. Indian. J. Med. Res., 140(6): 770-777.
Pattnaik, P., Roy, U., Jain, P. 1997. Biocolors: New generation additives for food. Indian Food Industry, 16(5): 21-32.

Richter, M., Kube, M., Bazylinski, D.A., Lombardot, T., Glöckner, F.O., Reinhardt, R., Schüler, R.D. 2007. Comparative genome analysis of four magneto tactic bacteria reveals a complex set of group-specific genes implicated in magnetosome biomineralization and function. J. Bacteriol., 189(13): 48994910.

Riquelme, C.A., Magida, J.A., Harrison, B.C., Wall, C.E., Marr, T.G., Secor, S.M., Leinwand. L.A. 2011. Fatty acids identified in the Burmese Python promote beneficial cardiac growth. Sci., 334(6055): 528-531.

Rokade, M.T., Pethe, A.S. 2016. Isolation and identification of chromogenic bacteria from various sources. EJPMR, 3(5): 295299.

Sahoo, A., Panigrahi, G.K. 2016. A review on Natural Dye: Gift from bacteria. Int. J. Bioassays, 5(9): 4909-4912.

Sarvamangala, D., Aparna, S.V. 2016. Microbial pigments-a short review. IOSRJESTFT, 10(8): 01-07.

Tibor, C. 2007. Liquid Chromatography of Natural pigments and synthetic dyes. $J$. Chromat. Library, 71: 11-19.

Young, S.L., Jeffrey Wilson, M., Miller, D., Hillier, S. 2008. Toward a comprehensive approach to the collection and analysis of pica substances, with emphasis on geophagic materials. PLoS ONE, 3(9): e3147.

doi:10.1371/journal.pone.0003147.

\section{How to cite this article:}

Parvathi, J.R., Shilpa Madhavan and Madhan Kumar, R. 2017. Applicability of Yellow Pigmented Microbe obtained from Indian Rock Python Fecal Sample as Bio-Ink. Int.J.Curr.Microbiol.App.Sci. 6(4): 1796-1803. doi: https://doi.org/10.20546/ijcmas.2017.604.215 